\title{
Comunicação pós-massiva de massa
}

\section{Mass post-mass Communication}

\section{Adilson Vaz Cabral Filho}

Professor Titular do Curso de Comunicação Social e do Programa de Pós-graduação em Mídia e Cotidiano (PPGMC) da Universidade Federal Fluminense (UFF). Coordenador do grupo de pesquisa EMERGE (Centro de Pesquisa e Produção em Comunicação e Emergência). Universidade Federal Fluminense, Programa de Pós-graduação em Mídia e Cotidiano, Niterói (RJ), Brasil.

\section{Introdução}

O estágio atual de desenvolvimento da Internet global impõe desafios para além da recorrente e até mesmo benevolente ideia de um ciberespaço dotado de uma cibercultura. Nem mesmo é suficiente a simpática ideia de um ambiente comunicacional, a despeito de uma proposta de transição que compreendia a Internet como um meio digital, para além dos meios analógicos tradicionais como rádio, televisão ou o conjunto dos meios impressos. Derivada de uma origem nos meios militares, impulsionada no meio acadêmico, disseminada em sua vertente comercial e consolidada no ambiente das mídias sociais, a Internet passa agora a enfrentar uma nova fase, compreendidos aqui seus limites, desafios e potencialidades, denominada aqui de Comunicação pós-massiva de massa.

Tendo como contraponto direto o livro Comunicação de massa sem massa, de Sérgio Caparelli (1980), compreende-se que o momento presente remete a comunicação a um outro momento histórico; uma nova etapa comunicacional se caracteriza pela capacidade de organização do massivo através da coleta e sistematização dos dados em um ambiente de mídia compreendido como pós-massivo, 
impulsionado a partir de uma nova onda conservadora em escala global, na qual o domínio tecnológico possibilita a fabricação de fluxos de verdade em prol dos interesses políticos e econômicos que os movem.

O artigo se divide em três partes: (1) a compreensão de processos pós-massivos e de desmassificação das mídias, por autores como George Gilder e Nelson Hoineff, mas também em como a TV se compreende ainda como a "nova televisão", de acordo com Michael Wolff, e como a economia da Internet se aproveita disso; (2) as novas formas de organização do massivo, num contraponto à crítica original à Comunicação de Massa, e a articulação de estratégias de propagabilidade (Cf. JENKINS ET AL., 2014) e controle dos algoritmos a partir da mineração de dados, como proposto por Vincent Mosco; e, por fim, (3) o reordenamento do controle dos fluxos informacionais pela via da big data, refletindo o caso da Cambridge Analytica e identificando seus operadores como os mesmos acionistas da velha política que sustentam historicamente o velho e o novo capitalismo desde o advento da indústria cultural.

Trata-se de um trabalho que se apoia fundamentalmente na bibliografia relacionada aos temas tratados, buscando descrever processos contemporâneos que contribuam para reforçar a argumentação aqui apresentada. O tema adquire especial relevância pela articulação de um domínio tecnológico que, ao mesmo tempo que nos parece distante, está suficientemente próximo para conformar decisões e definições de rumo capazes de delinear os próximos caminhos da história da humanidade.

Tais processos estão envoltos numa caixa preta ainda mais difícil de ser desvendada que os tradicionais grupos produtores e distribuidores de mídia, mas que, colocado o desafio, demandará um significativo engendramento sobre o sentido de bem público que precisamos atribuir à Internet, dada a capacidade de se constituir num ambiente comunicacional dessa magnitude para o benefício de seus usuários e da população em geral.

\section{Pós-massiva e desmassificada: a mídia desconstruída}

O esgotamento do caráter massivo da mídia é não apenas um fenômeno bastante consolidado entre o pensamento crítico na Comunicação e na Cultura, como também um incômodo entre os próprios profissionais de Marketing e de Comunicação no âmbito das corporações. As contas simplesmente não fecham, e o pensamento de que produtos e serviços devem ser colocados à disposição para consumidores 
que devam se mostrar dispostos está sendo contínua e amplamente superado pelas dinâmicas do próprio mercado.

Desse modo, não é apenas a introdução de tecnologias que torna possível às mídias identificar segmentos sociais, nichos de consumidores e, mais recentemente, implementar interações customizadas com clientes, ao modo do filme Minority Report, de Steven Spielberg. Trata-se de uma demanda mercadológica, operada na própria reorientação do capital, que proporcionou uma ambientação na qual homens atuam maquinicamente e mercados assumem sentimentos de nervosismo ou tranquilidade, como também um discurso de legitimação que assume trabalhadores como colaboradores em suas empresas e faz de consumidores participantes ativos em processos produtivos. Assim chamados prosumidores, estes são especialmente atuantes junto a produtos e empresas dos quais são fãs, as lovemarks.

Nesse cenário é que aparece o dilema da desmassificação e a consequente viabilidade de uma mídia pós-massiva, contraponto ao proposto por Caparelli (1980) em Comunicação de massa sem massa, um dos estudos pioneiros que demonstram a concentração dos meios de comunicação de massa, que, em função de suas movimentações políticas e econômicas, reforçam a exclusão da massa em seus produtos e processos. Nesse cenário mais recente, se cabe reconhecer que, "por meio de dispositivos móveis, estaríamos vendo a expansão de territórios comunicacionais e informacionais de ação política e de movimentação social no espaço urbano", como ressaltam Lemos e Lévy (2010, p. 72), é necessário compreender que a celebrada democratização do pólo de emissão aberto e sem controle não necessariamente resulta num ambiente caracterizado pelo conversacional.

Se a mídia convencional já trabalhava com o problema dos "500 canais e nada para ver" (HOINEFF, 1996, p. 43), a pulverização de ferramentas, recursos e formatos para a produção e a veiculação de conteúdos multimídia, bem como de espaços para a participação e o posicionamento em assuntos diversos, proporciona a usuários de Internet em geral um ambiente em que muitos se expressam, e poucos realmente ouvem.

Um maior número de produtores independentes encontrou mais espaços para escoar conteúdos e viabilizar suas iniciativas, mas dentro de uma lógica de mercado reconfigurada em relação à televisão massiva, a partir da lógica de um ambiente assentado no suporte digital: mecanismos de busca, configuração de hierarquias de oferta de conteúdo com base em critérios estratégicos pelas empresas que 
viabilizam plataformas de mídias sociais, sobre os quais seus usuários não têm controle direto, mas apenas manipulam opções limitadas que permitem uma limitada sensação de preservação de seus dados.

Em Telecosmo... (2001), George Gilder, então assessor da Casa Branca no governo de Ronald Reagan, decreta o fim da era de expansão do computador. Com a mesma eloquência com a qual havia decretado o fim da televisão em $A$ vida após a televisão, seu livro anterior, o autor dá continuidade à desconstrução da ideia do massivo como componente dos meios de comunicação. Se, para Gilder, a televisão tem seu fim evidenciado em virtude das novas tecnologias e modos de organização dos produtos e conteúdos, o computador perde seu protagonismo em favor da infraestrutura de rede e da conformação de um ambiente multimidiático e multiplataforma, movido pela ampliação da largura de banda e pela otimização dos fluxos de conteúdos.

De forma alguma isso implica afirmar que televisões e computadores serão desnecessários, substituídos ou superados, mas sim que viriam a perder seu protagonismo em virtude de um ambiente de rede cujos ingredientes estavam começando a amadurecer. O próprio Gilder $(2001$, p. 298) reforça a apologia às redes ao afirmar que

no sistema ideal, a complexidade está na mensagem em vez de no meio. Eliminando a entropia das redes movendo-as para as ondas puras de luz - você pode aumentar sua capacidade de transmitir informação. Outra palavra para uma portadora de baixa entropia é rede burra. Quanto mais burra a rede, mais inteligência ela poderá transportar.

Com o foco nos aparatos tecnológicos que constituíam a comunicação massiva deslocada para o ambiente da rede, a ideia da inteligência relacionada ao transporte de conteúdos se afinava mais com a expectativa de uma Internet como libertadora do pólo de emissão, ao modo de seus principais precursores. No entanto a defesa da liberdade de expressão manifesta na expectativa de George Gilder (2001, p. 283) não deixa qualquer suspeita quanto a sua contundência: “(...) muitas pessoas ainda têm problemas compreendendo como ela [a televisão] reconhecidamente consome tempo, como é um modelo de negócios obsoleto, como a tecnologia é atávica e como sua força cultural é cômica (...)”.

A crítica às empresas dos grandes meios de comunicação convencionais encontrou na massa o elemento estranho a ser desconstruído. O diálogo com um grande contingente de pessoas sem a devida caracterização não apenas era sem sentido, mas sem propósito e precisaria ser transposto. Não bastava buscar a segmentação de mercados em programas dirigidos a determinados públicos, mas compreender as 
pessoas em suas diferenças, bem como em suas potencialidades de produção, num ambiente que funcionasse mais como uma plataforma na qual todos operassem de modo proporcional.

Dessa forma, as grandes corporações de mídia se viam diante de um impasse, tratado mais detidamente por Nelson Hoineff em seu livro A nova televisão... (1996). Para o autor, "o que o público busca na televisão não são canais, mas programação" e salienta ainda que "se por esses canais fluísse uma programação mais ética, a televisão aberta certamente teria sido melhor" (HOINEFF, 1996, p. 179). Da mesma forma que Gilder, ele foca o problema do impasse das grandes redes na existência de um terminal inicialmente concebido, e sempre tratado, como inteligente por parte dos grupos de mídia, mas que se tornou padronizado, anacrônico e inadequado para a demanda de diferentes segmentos de público. No entanto, a despeito de Gilder, acreditava num possível reordenamento que pudesse estreitar interesses de emissora e audiência, o que amplamente demonstrou não estar acontecendo nem na TV aberta, nem na TV por assinatura, salvo raras exceções.

O impasse não se resolveu no âmbito das empresas controladoras de terminais "burros", sejam eles televisores ou computadores, mas na desconstrução de produtos dirigidos a públicos comuns e na oferta de redes tão amplas quanto heterogêneas. A diversificação de espaços de produção e circulação de conteúdos, apesar de caracterizar o estabelecimento de uma comunicação pós-massiva, não chegou necessariamente a expressar uma transformação pautada no que Chris Anderson (2006) denominou cauda longa: os assim chamados hits seguem mobilizando atenção, gerando mais conteúdos e, significativamente, mais valores do que o grande contingente de iniciativas pulverizadas. Conformam o que vem sendo chamado de uberização da economia (não apenas digital: Cf. HILL, 2015), embora o ambiente da rede tenha passado a viabilizar novas tecnologias de controle, pautadas na busca e nos dados obtidos pelos rastros dos usuários, a partir do acesso a serviços e recursos disponibilizados na rede. São as novas configurações do massivo, que serão abordadas a seguir.

\section{As novas formas de organização do massivo}

A crítica do caráter massivo por parte da atuação dos grupos de mídia não necessariamente é destinada ao ethos da indústria cultural, mas apenas ao seu modus operandi, em especial às produções jornalísticas. Abarcar um maior número de pessoas num tempo menor e a custos menores nunca esteve 
no alvo de críticos conservadores de governo ou do mercado, mas sim uma melhor eficiência na relação entre produtores e consumidores de conteúdo midiático.

Desse modo, nunca se deixou de perseguir o grande público a partir do ambiente digital. Se a crítica original à Comunicação de Massa se dava no trato de como produtores de conteúdo assumiam canais pelos quais se transmitem conteúdos sob o selo de qualidade dos próprios grupos de mídia, o desafio presente consiste em compreender as novas formas de organização do massivo, que envolvem tanto a articulação de estratégias de propagabilidade (Cf. JENKINS ET AL., 2014), como a extração e mineração de grandes dados (data mining / big data) a partir do controle de algoritmos, compreendidos aqui como "uma sequência finita de passos que se usa para resolver um problema", tal como propõem Christian e Griffiths (2017, p.13), numa definição mais abrangente do que a restrita a máquinas.

A proposta da Cultura da conexão (JENKINS ET AL., 2014) é oferecer uma visão atenta sobre como criar significado e valor num mundo comunicacional em constante mutação. Trata-se de um desdobramento da visão apresentada em livro anterior, sobre a Cultura da Convergência, cujo intuito era "ajudar pessoas comuns a entender como a convergência vem impactando as mídias que elas consomem e, ao mesmo tempo, ajudar líderes da indústria e legisladores a entender a perspectiva do consumidor a respeito dessas transformações" (JENKINS, 2009, p. 39). Gerar valor e significado equivale, portanto, a convergir interesses na busca por conteúdos capazes de serem legitimados pelos usuários, e, para tanto, compreender estratégias para a conquista de grandes contingentes de audiência volta a ser uma motivação.

Ainda em Cultura da convergência (2009), Henry Jenkins requenta o conceito de cultura participativa para os meios digitais em rede, mais relacionados às interações sociais de comunidades de fãs que acionam modos de se diferenciar de meros espectadores. Essa cultura é capaz de gerar fenômenos tão distintos quanto as fanfics (histórias criadas por fãs a partir de personagens e produtos admirados) ou os prosumidores (consumidores que contribuem com alterações ou melhorias para produtos e serviços dos quais são fãs), sem falar no desenvolvimento de peças próprias de campanha política, capazes de gerar fluxos de distribuição de conteúdos em comunidades de compartilhamento próprias.

As mídias propagáveis aparecem numa plataforma não só digital, mas convergente, em que "facilitações da mídia digital funcionam como catalisadoras para a reconceituação de outros aspectos da 


\section{ALCEU}

ISSN: $2175-7402$

cultura, exigindo que sejam repensadas as relações sociais, que imaginemos de outro modo a participação cultural e política (...)" (JENKINS ET AL., 2014, p. 5). Parte desse repensar diz respeito ao contraste entre o massivo relacionado às mídias tradicionais, cujos conteúdos são empurrados aos telespectadores, e um novo massivo, a partir de ferramentas, recursos e modelos de negócios proporcionados, especialmente, pelas empresas de mídia controladoras das plataformas acoitadoras das mídias sociais.

Esse também não deixa de ser um componente que se pretende na mão do usuário-prosumidor, mas acaba sendo confrontado com a realidade de um ecossistema composto por corporações de mídia muito mais potentes, que controlam não a infraestrutura das redes disponibilizada, mas a camada de conteúdos que trafega acima dela. Assim, não é possível acolher o modelo mais participativo de cultura defendido pelos autores, no qual pessoas "estão moldando, compartilhando, reconfigurando e remixando conteúdos de mídia de maneiras que não poderiam ter sido imaginadas antes" (JENKINS ET AL., 2014, p. 4).

Este modelo pode até acontecer em escala restrita, dentro de excepcionalidades, mas está longe de ser representativo na Internet por dois motivos: as corporações de mídia tradicional seguem produzindo seus conteúdos com a devida sustentação de anunciantes em torno de um ambiente profissional, agendando temas, acontecimentos e personagens que compõem conteúdos amplamente distribuídos, e as corporações contemporâneas de mídia conseguem rastrear movimentos de usuários e gerir os dados que estes disponibilizam, dando pistas para a reconfiguração do massivo no ambiente pós-massivo.

Vincent Mosco reúne, na ampla e profunda crítica apresentada em Becoming Digital... (2017), o principal instrumental relacionado a essa reconfiguração do controle midiático a partir da recomposição do massivo. Articula sua análise a respeito do que chama a próxima Internet ou, ainda, o mundo pós-Internet, que compreende a expansão de empresas e a flexibilização do ambiente regulatório em torno da convergência de serviços de navegação em nuvem, mineração de grandes dados, Internet das coisas, além da inteligência artificial, do aprendizado de máquina, sem deixar de mencionar a Deep Web e a Dark Web. Mosco $(2017$, p. 5) apresenta uma crítica pela Economia Política que compreende o conjunto dessas mudanças como "uma ferramenta para expandir a democracia, empedrar as pessoas em todo o mundo, prover mais necessidades da vida e avançar na equidade social", mas, apesar disso, lembra, "está sendo primeiramente usada para alargar a comodificação e a militarização do mundo". 
Embora a convergência proporcionada pelas novas tecnologias acabe por deslocar a crítica a esses novos operadores, cabe salientar aqui que as transformações presentes realinham os grupos de mídia tradicional ao conjunto dessas mudanças, seja oferecendo insumos para impulsionar o volume de novos conteúdos, seja estabelecendo parcerias ou realinhamentos empresariais para enfrentar esses novos tempos.

É aqui que se configura o realinhamento da comunicação pós-massiva, proporcionada pelas infraestruturas de rede e serviços por ela transportados, com a manipulação de dados disponibilizados por usuários legitimadores não apenas de um ou outro serviço ou recurso que potencialize interações e compartilhamento de dados, mas da própria plataforma que materializa o ambiente comunicacional no qual a Internet se constituiu e amadureceu.

A potencialidade de emissão por parte dos usuários é significativa, apesar de sempre ser acessível através de mecanismos de interatividade e de descentralização já existentes na radiodifusão. Novos e distintos produtos e serviços passam a existir por parte da ação de novos entrantes, na medida de um ambiente que potencializa e acomoda essas entradas. A complexidade e o vigor dessas mudanças implica a adaptação de formatos, serviços e mesmo produtos por parte dos meios que trabalhavam dentro de outras lógicas (estratégias em torno do "jornalismo cidadão" são o exemplo mais significativo dessas transformações).

No entanto a contrapartida cobrada dos usuários que conformam esse ambiente é o fornecimento amplo de dados e rastros de navegação, transformados em informação para a compreensão de empresas e governos. A extração e a mineração desses dados em escala massiva é o que proporciona o que aqui se apresenta como comunicação pós-massiva de massa, ou seja, o massivo reconfigurado a partir de um ambiente movido pela sua estigmatização, com incidência em diversas dinâmicas e definições sociais e políticas.

A necessidade da regulamentar e regular o ambiente da Internet, identificando papéis, responsabilidades e possibilidades nesse ambiente por parte de Estado, Mercado e sociedade em geral vem sendo reconhecida cada vez mais, inclusive por pesquisadores e simpatizantes nas mais diversas áreas. Da mesma forma, entender limites da pretensa democratização do acesso aos dados em sua complexidade se torna cada vez mais evidente. Cabe identificar as implicações dessa contrapartida da 
liberação do pólo emissor, que nos capacitou a ser produtores de conteúdos para nossa própria audiência, mas que mesmo assim vêm sendo disponibilizados a partir de critérios de cuja formulação não participamos e que não se colocam transparentes. Além disso, administram dados que fornecemos ao modo que bem definem, sem que se estabeleçam critérios públicos de controle e transparência dos dados.

\section{Desafios ao reordenamento do controle massivo}

A ampla divulgação do caso da Cambridge Analytica nos jornais levantou mais uma vez o problema da fragilidade dos dados que usuários dispõem na Internet e, em especial, em sites de redes sociais como o Facebook e o Twitter. Segundo noticiou The Guardian (2019), entre outros jornais, informações pessoais de 50 milhões de perfis foram obtidas por um pesquisador externo para fins acadêmicos. Investigações posteriores e notícias tornaram visíveis a participação direta do Facebook no acesso e na gestão desses dados, o que foi compreendido como violação de segurança por parte da empresa e chegou a levar seu fundador, Mark Zuckerberg, a depor no parlamento europeu.

A trama tornou-se possível a partir de denúncias de uma fonte não informada, que detinha informações estratégicas e significativas para caracterizar o comportamento das empresas envolvidas e o procedimento adotado. Poderiam ser Edward Snowden, Julian Assange ou qualquer um com acesso a informações privilegiadas, dispostos a furar o bloqueio de um ambiente corporativo que nos envolve a todos, colocando-se na contramão de uma expectativa de comportamento que mantém e faz girar o sistema, podendo incidir tanto em questões econômicas como políticas das mais diversas.

Revela uma sistemática de funcionamento de processos que deveriam estar ao alcance de todos e ser publicamente regulados, para além de governos, compreendendo mecanismos permanentes e contínuos de cogestão. Na primeira metade da primeira década do século XXI, a ONU concluiu sua série de conferências multilaterais instituídas desde a Rio 92 com a realização da Cúpula Mundial da Sociedade da Informação (CMSI), realizada em duas etapas: 2003, em Genebra, e 2005, na Tunísia. Entre outras decisões, foi estabelecida a criação do Fórum de Governança da Internet, cujo propósito seria implementar o que foi definido e dar continuidade ao que ficou em aberto no debate entre governos. 
No Brasil, a criação do Comitê Geral da Internet Brasil (CGI.Br) já havia proporcionado considerável contribuição e referência ao estabelecimento de mecanismos regulatórios em nível mundial. Organizado de forma tripartite, o comitê é responsável pela elaboração de políticas que dizem respeito à distribuição das responsabilidades de distintos atores em relação à infraestrutura e aos serviços disponibilizados para o bom funcionamento da Internet no país.

Após vários debates no meio jurídico, político e social, contando também com a notícia de um vazamento de dados públicos estratégicos, a então presidenta Dilma Rousseff promulgou o Marco Civil da Internet (BRASIL, 2014), com o intuito de estabelecer "princípios, garantias, direitos e deveres para o uso da Internet no Brasil”, mas que chegou a deixar medidas em aberto, algumas delas definidas com a Lei Geral de Proteção de Dados, ao final do governo Temer (BRASIL, 2018).

Busca-se compreender, com esse breve histórico, que existe e persiste a organização da sociedade em torno do enfrentamento ao controle por parte de empresas detentoras dos meios de produção desse ambiente comunicacional, buscando proporcionar garantias aos usuários e um ambiente que nos seja menos hostil. Organizações como a SaferNet ${ }^{1}$, o ITS ${ }^{2}$, o Artigo $19^{3}$, entre outras, se esforçam em construir esse debate junto ao legislativo, mas também sensibilizar usuários a respeito de temas que implicam numa maior atenção a respeito do uso da Internet no cotidiano, especialmente em relação à exposição dos dados pessoais.

Cristina de Luca (2019) escreveu em seu blog uma reportagem em que proclama o fim da era do uso irresponsável dos dados, atualizando posicionamentos envolvidos a respeito do debate recente no Brasil e no mundo. Para a jornalista, "o que se espera hoje do empreendedor que trabalha com tecnologia é muito mais do que somente a entrega de um produto sustentável e escalável". Esse é, em resumo, o debate em torno do qual se coloca o enfrentamento do controle por parte das grandes corporações, em função da queda vertiginosa da tolerância ao uso indevido de dados.

Apesar de um resistente e crescente movimento em torno dessa direção, com incidência em alguns parlamentos e órgãos de governo, sob pressão de organizações da sociedade, as evidências apontam ao sentido contrário, em que a sociedade, em geral, não apenas legitima as plataformas em rede

\footnotetext{
${ }^{1} \mathrm{http}: / /$ www.safernet.org.br/

${ }^{2}$ http://www.itsrio.org/

${ }^{3}$ http://www.artigo19.org/
} 
proporcionadas pelo ambiente comunicacional da Internet, como as reforça. Alimenta com dados que caracterizam disposições para um hiperconsumo, ao contrário do defendido por Gilles Lipovetsky (2007), bem como afirma o culto ao amador, tal como proposto por Andrew Keen (2009), permitindo a usuários em geral uma sobrepotência que habilita posicionamentos sobre qualquer assunto, independentemente de competências construídas para tal. Iniciativas relacionadas à conscientização do consumidor, ao combate às fake news em tempos de pós-verdade, ao desligamento de usuários das mídias sociais (sendo o facebookcídio uma de suas formas populares) e mesmo à busca pela legitimação da produção sistemática de pesquisa e conhecimento consistem em resistências importantes, mas pontuais a um movimento articulado pelo agenciamento corporativo de dados em grande escala, potencializado por uma nova onda conservadora global alimentadora desse ambiente.

A proposta de Manuel Castells (2007, p. 248) é também instigante, porém desafiadora. Trata-se da existência de uma nova forma de comunicação socializada, a qual denominou autocomunicação de massa. Ensaiada em livros anteriores - Comunicação e poder e Redes de indignação e esperança -, sua proposta compreende uma forma de comunicação de massa que alcança potencialmente uma audiência global através de redes ponto a ponto; multimodal, em que a digitalização de conteúdos e softwares sociais avançados permitem reformatar quase todo conteúdo em quase todo formato, além de autogerada em conteúdo, autodirecionada em emissão e autosselecionada em recepção, em que muitos comunicam com muitos.

O desafio que aqui se impõe é justamente compreender que a inviabilidade dessa proposta é característica da expansão e da captura da Internet pelas grandes corporações. Cabe identificar e desvelar mecanismos que inviabilizam sua existência e seu modus operandi, alargando a compreensão dos usuários a respeito de seus usos, bem como promovendo e articulando organizações de pressão por iniciativas regulatórias e de regulamentação que tornem o ambiente da Internet mais transparente e seguro, como vem propondo-se a fazer a Coalizão Direitos na Rede ${ }^{4}$.

Da mesma forma, outro desafio é confrontar e renovar textos atuais sobre Internet, incluindo os mais críticos, que parecem anacrônicos diante da consolidação dos atuais mecanismos de controle. Suas aplicações e complexidades não mais se restringem às mídias sociais, mas ampliam seus tentáculos a partir

\footnotetext{
${ }^{4}$ https://direitosnarede.org.br/
} 
da mineração de dados e da capacidade de fabricar usuários e reputações nas redes (curtidas e outras formas de demonstração de emoções, conforme cada mídia social), através da manipulação de grandes dados que chegam até a incidir no resultado de processos eleitorais de alguns países.

Vale, por fim, entender ainda que a televisão é a nova televisão, tal como proposto por Michael Wolff (2015). Para o autor, a despeito de toda euforia em torno das novas tecnologias de informação e comunicação em rede, a televisão, bem como toda a indústria que a sustenta, segue como meio de referência na indústria de comunicação, cultura e entretenimento. Em suas palavras, "além de ser muito mais do mesmo (possivelmente tanto um retrocesso quanto um avanço), a tecnologia digital não refinou ou mudou de fato a experiência do vídeo - nem para o público nem para o anunciante" (p. 157). Wolff cogita, inclusive, que a experiência tenha diminuído em virtude da qualidade mais baixa e da adoção de uma publicidade mais forçada.

Isso resulta, no entanto, na compreensão da lógica de funcionamento de uma outra televisão, distinta da construção de seu reinado, na segunda metade do século XX. Antes legitimada como meio principal em relação ao conjunto de outros complementares que apenas repercutiam seus conteúdos, a televisão passa a sofrer um deslocamento em seu papel no conjunto dos meios de comunicação que coexistem em um ecossistema mais complexo, não abdicando do papel de referência na composição de conteúdos produzidos e distribuídos.

O YouTube que o diga 5 : somente esta plataforma de veiculação de vídeos disponibiliza 300 horas de vídeo por minuto e são assistidos a 5 bilhões de vídeos por dia (OMNICORE, 2019). Números que fazem frente a muitos grupos de mídia em todo o mundo, mas que dizem respeito a um grande contigente de conteúdos - e tráfego - oriundo de emissoras de TV imbuídas em adotar estratégias de atuação multiplataforma para enfrentar os desafios desse cenário de convergência, fazendo o que sempre fizeram desde o advento da indústria cultural: tentar alcançar o interesse do público, pois deste se compõe sua mais valiosa mercadoria.

Apesar de compreenderem o YouTube como um site de ruptura cultural e econômica, Burgess e Green (2009, p. 33) não consideram essa ferramenta como distinta da televisão convencional. Para eles,

\footnotetext{
${ }^{5}$ Bem como, mais recentemente, seus equivalentes IGTV, do Instagram, e o Watch, do Facebook.
} 
esses momentos de transição de mídia não deveriam ser classificados como rompimentos históricos radicais, mas sim como períodos de turbulência crescente, que se tornam visíveis conforme as várias práticas, influências e ideias preestabelecidas competem com as emergentes como parte da longa história da cultura, mídia e sociedade. O YouTube não representa uma colisão e sim uma coevolução aliada a uma coexistência desconfortável entre "antigas" e "novas" aplicações, formas e práticas de mídia.

Tal como assinalado por Cristina de Luca, princípios relativos ao resgate e à afirmação do caráter público da comunicação, como a universalidade, a equidade e a comunicação aberta, precisam ser resgatados e serão incompatíveis com a sustentabilidade do ecossistema da Internet. Mosco (2017, p. 209) reivindica que esses princípios, criados em meio a batalhas pelo controle de um sistema de comunicação relacionado à concentração da propriedade, regulação (entenda-se aqui por restrição) do interesse público, comercialização excessiva, neutralidade da rede, entre outros fatores, não podem ser esquecidos (bem como as batalhas envolvidas), no sentido de se "considerar novamente a necessidade da utilidade pública na comunicação".

\section{Considerações finais}

Se, em Comunicação de massa sem massa, Sérgio Caparelli (1980) propõe uma crítica à organização do massivo a partir da afirmação de um pensamento único, sem deixar de apontar a importância de uma mídia alternativa ("sem massa") no enfrentamento da comunicação de massa, o momento presente diz respeito à reconfiguração do massivo a partir de um ambiente movido pela sua própria estigmatização, tal como propõem Gilder e Jenkins.

Não se trata neste artigo de, ao modo de Dominique Wolton (1996), tecer motivações para o elogio do grande público, mas de reconhecer que o controle a partir do massivo é uma demanda intrínseca do capital. Além disso, que a transição do analógico para o digital, inicialmente compreendida como potencializadora de uma expressividade libertadora e democrática, resultou na maturação de uma plataforma na qual os dados dispostos pelos usuários, tidos como supostamente beneficiados pela aclamada libertação do pólo da emissão, passaram a servir como commodities para a exploração de indústrias diversas e para a alimentação de uma imensa indústria alimentada pela gestão da informação.

Propõe-se, portanto, um reordenamento da disposição para compreender a Internet como plataforma a ser defendida e afirmada. Mas, longe de ser libertária ou anárquica, um ambiente que 


\section{ALCEU}

ISSN: $2175-7402$

demanda regulamentação e regulação com controle social e globalmente articulado. Apesar de, sim, contar com aspectos positivos, a liberação do pólo da emissão traz contrapartidas indesejáveis, que precisam ser enfrentadas com a devida profundidade, pois a maturação e a complexidade da Internet estão implicando a construção e desconstrução de carreiras, empreendimentos e mesmo governos.

Enquanto pessoas puderem ainda programar as máquinas e configurar as redes, serão ainda responsáveis pela construção político-econômica dos processos implementados, mesmo que submetidas a um ambiente econômico opressivo e controlador. Mas a submissão a uma lógica maquínica pode nos fazer entregar facilmente nossa condição humana, seja através da submissão ao sistema radicalmente burocrático, seja a partir da reposição de trabalhadores humanos por robôs ou mesmo algoritmos ou códigos de programação. Seria a entrada numa nova era do Marketing, uma espécie de Marketing 5.0, na qual se estabeleceria a consolidação da distopia da humanização das máquinas e da robotização das pessoas.

Diante da existente disposição para efetivar esse cenário, cabe esgarçar a disposição crítica para enfrentar modelos teóricos com receitas fáceis de viabilidade da existência e sobrevivência neste novo cenário. Especial atenção deve ser dada às armadilhas relacionadas à redefinição e recontextualização de conceitos como participação e engajamento, bem como legitimação e reputação, entre outros, como se inventados ou efetivamente existentes a partir da assim aclamada revolução digital. Impossível desconsiderar a importância e mesmo as implicações de temas como a mineração dos dados, a classificação de nichos de consumo e identificação de tendências de usos, bem como a importância da regulamentação e da regulação por parte de países, regiões (como o Parlamento Europeu e o Mercosul, entre outros) e organizações multilaterais da ONU ${ }^{6}$.

Esse ecossistema pós-massivo oferece desafios extremamente mais complexos que os proporcionados pela consolidação da indústria cultural, com a expansão do rádio e da TV. Não se trata apenas de um ambiente estruturado em torno da divisão entre produtores e receptores de conteúdos, no qual se tornava evidente a disparidade do acesso aos meios para expressão de distintas perspectivas, que também não dispunha do acesso a dados qualificados a respeito de seus usuários.

\footnotetext{
${ }^{6}$ Em especial a União Internacional de Telecomunicações (UIT), a Organização das Nações Unidas para a Educação, a Ciência e a Cultura (UNESCO), a Organização Mundial do Comércio (OMC) e a Organização Mundial de Propriedade Intelectual (OMPI).
} 
Em seu lugar, efetiva-se um ambiente comunicacional no qual se vende a potencialidade de que todos são produtores, que todos podem acessar e utilizar recursos e serviços na medida do domínio de como colocá-los em funcionamento e que ainda podem obter vantagens diferenciais de afirmação num mercado cada vez mais competitivo e escasso, no qual pessoas, mesmo dotadas de múltiplas competências, são substituídas por máquinas programadas - ainda! - por humanos, que aparentemente reforçam o respaldo e dão sentido a esta dominação.

Não se trata mais do monstro "Macobeba maldito, que devora o mato e o mito, rádio, jornal e TV"7, como no samba-enredo da escola carioca Unidos da Tijuca, mas de um vilão complexo como Thanos, personagem Marvel dos quadrinhos e popularmente conhecido a partir do filme Vingadores: guerra infinita, que aniquila populações com a pretensão de promover a sustentabilidade do universo, gerando males quase que irreversíveis a partir de uma motivação supostamente boa. Uma visão significativamente mais complexa, diante da qual não podemos nos esquivar de um posicionamento sistêmico e crítico.

Adilson Vaz Cabral Filho

ORCID: https://orcid.org/0000-0001-8132-6675 Universidade Federal Fluminense, Programa de Pós-graduação em Mídia e Cotidiano, Niterói (RJ), Brasil. Doutor em Comunicação Social pela Universidade Metodista de São Paulo E-mail: acabral@comunicacao.pro.br

Recebido em: 29 de setembro de 2020.

Aprovado em: 9 de outubro de 2021.

\footnotetext{
7 TRINDADE, Celso; Azeitona; PEREIRA, Ronaldo Santos; SILVA, Ivar; SANTOS, Edmundo Araújo; PIZZOTTI, Orlani Silva; SOUZA, Sebastião de. G.R.E.S. Unidos da Tijuca: Macobeba, o que dá pra rir, dá pra chorar. Intérprete: Sobrinho. In: Sambas de Enredo Especial 1981. Lado B, faixa 4.
} 


\section{Referências:}

ANDERSON, C. A cauda longa: do mercado de massa para o mercado de nicho. Rio de Janeiro: Ed. Campus, 2006.

BRASIL. Casa Civil. Lei Geral de Proteção de Dados. Lei no 13.709, de 14 de agosto de 2018. Disponível em http://www.planalto.gov.br/ccivil_03/_Ato2015-2018/2018/Lei/L13709.htm. Acesso em 12/02/2019.

- Marco Civil da Internet. Lei no 12.965, de 23 de abril de 2014. Disponível em http://www.planalto.gov.br/ccivil_03/_ato2011-2014/2014/lei/I12965.htm. Acesso em 12/02/2019.

CAPARELLI, S. Comunicação de massa sem massa. São Paulo: Ed. Cortez, 1980.

CASTELLS, M. Communication, Power and Counter-power in the Network Society. In International Journal of Communication. 1, 2007, p. 238-266.

CHRISTIAN, B. e GRIFFITHS, T. Algoritmos para viver: a ciência exata das decisões humanas. São Paulo: Ed. Companhia das Letras, 2017.

GILDER, G. Telecosmo, a era pós-computador: como a infinita largura de banda irá revolucionar o mundo. Rio de Janeiro: Ed. Campus, 2001.

BURGESS, J. e GREEN, J. YouTube e a revolução digital: como o maior fenômeno da cultura participativa está transformando a mídia e a sociedade. São Paulo: Ed. Aleph, 2009.

HILL, S. Raw Deal: How the "Uber Economy" and Runaway Capitalism Are Screwing American Workers. New York, St. Martin's, 2015.

HOINEFF, N. A nova televisão: desmassificação e o impasse das grandes redes. Rio de Janeiro: Ed. RelumeDumará, 1996.

JENKINS, H.; GREEN, J.; FORD, S. Cultura da conexão: Criando valor e significado por meio da mídia propagável. São Paulo: Ed. Aleph, 2014.

. Cultura da convergência. São Paulo: Ed. Aleph, 2009.

KEEN, A. O culto do amador: como blogs, MySpace, YouTube e a pirataria digital estão destruindo nossa economia, cultura e valores. Rio de Janeiro: Ed. Zahar, 2009.

LEMOS, A.; LÉVY, P. O Futuro da internet: em direção a uma ciberdemocracia planetária. São Paulo: Ed. Paulus, 2010.

LIPOVETSKY, G. A felicidade paradoxal: ensaios sobre a sociedade de hiperconsumo. São Paulo: Ed. Companhia das Letras, 2007. 
LUCA, C. de. 2019. A era do uso irresponsável dos seus dados está chegando ao fim. Disponível em https://porta23.blogosfera.uol.com.br/2019/02/08/a-era-do-uso-irresponsavel-de-dados-esta-chegandoao-fim/. Acesso em 11/02/2019.

MOSCO, V. Becoming digital: toward a Post-Internet Society. Bingley: Emerald, 2017.

OMNICORE. YouTube by the Numbers: Stats, Demographics \& Fun Facts, 2019. Disponível em https:/www.omnicoreagency.com/youtube-statistics/. Acesso em 13/02/2019.

THE GUARDIAN. The Cambridge Analytica files, 2019. Disponível em https://www.theguardian.com/news/series/cambridge-analytica-files. Acesso em 12/02/2019.

WOLFF, Michael. Televisão é a nova televisão: o triunfo da velha mídia na era digital. São Paulo: Ed. Globo, 2015.

WOLTON, Dominique. Elogio do grande público: uma teoria crítica da televisão. São Paulo, Ed. Ática, 1996.

\section{Resumo}

Compreendendo a Internet como um ambiente comunicacional pós-massivo, que possibilita fabricar e consolidar verdades em prol de interesses distintos por parte dos sujeitos que as movem, esta pesquisa reforça a dimensão massiva dessa comunicação, a partir de uma abordagem que parte da compreensão de processos pós-massivos e de desmassificação das mídias, como a TV se afirma como "a nova televisão" e como a economia da Internet se aproveita disso; em seguida, reflete a articulação de estratégias de propagabilidade e controle dos algoritmos a partir da mineração de dados e, por fim, enfoca o reordenamento do controle de informações pelo big data, identificando seus operadores como os que sustentam o velho e o novo capitalismo desde o advento da indústria cultural.

Palavras-chave: Mídia pós-massiva. Internet. Big data.

\section{Abstract}

Understanding Internet as a post-mass communicational environment, that allows the creation and consolidation of truths in favor of distinct interests by the ones that move them, this research reinforce the massive dimension of this communication, addressing the comprehension of postmass processes and media desmassification, but also how TV is affirmed as "the new television" 
and how Internet economy takes advantage of that; then, it's reflected the articulation of spreadability strategies and algorithms control from data mining and the reordering of the control of informational flows through big data and, finally, it focuses on the reorganization of information control by big data, identifying its operators as those who have supported old and new capitalism since the advent of the cultural industry.

Keywords: Post-mass media. Internet. Big data.

\section{Resumen}

Entendiendo Internet como un entorno comunicacional post-masivo, que permite fabricar y consolidar verdades a favor de diferentes intereses por parte de los sujetos que las mueven, esta investigación refuerza la dimensión masiva de esta comunicación, a partir de un enfoque que parte de la comprensión de los procesos post-masivos y desmasantes de los medios, ya que la TV se afirma como "la nueva televisión" y cómo la economía de Internet se aprovecha de ella; luego, refleja la articulación de estrategias algorítmicas de propagabilidad y control basadas en la minería de datos y, finalmente, se enfoca en el reordenamiento del control de la información por big data, identificando a sus operadores como aquellos que han apoyado al viejo y nuevo capitalismo desde el advenimiento del industria cultural.

Palabras clave: Post-Mass Media. Internet. Big data.

Este artigo é publicado em acesso aberto (Open Access) sob a licença Creative Commons Attribution Non-Commercial (CC-BY-NC 4.0), que permite que outros remixem, adaptem e criem a partir do seu trabalho para fins não comerciais, e embora os novos trabalhos tenham de lhe atribuir o devido crédito e não possam ser usados para fins comerciais, os usuários não têm de licenciar esses trabalhos derivados sob os mesmos termos. 